\title{
Current and Emerging Therapies for Diabetic Retinopathy
}

a report by

\section{Dal W Chun, MD}

Vitreoretinal Specialist at the Ophthalmology Service of Walter Reed Army Medical Center in Washington, DC. DOI: 10.17925/USOR.2006.00.00.13

Diabetes mellitus (DM) is an important cause of visual morbidity that affects an estimated 11.8 million diagnosed and 4.9 million undiagnosed individuals in the US. ${ }^{1}$ Among individuals 40 years and older with $\mathrm{DM}$, it is estimated that $40.3 \%$ have some degree of diabetic retinopathy (DR) and $8.2 \%$ have visionthreatening retinopathy. ${ }^{2}$ The rates of retinopathy and vision-threatening retinopathy are higher in individuals with type 1 DM, occurring in $82.3 \%$ and $32.2 \%$ of affected individuals, respectively. ${ }^{3}$ The medical cost of DR has been estimated to be US $\$ 500$ million per year in the US alone. ${ }^{4}$ In addition, individuals with visual loss secondary to DR suffer from a substantial decrease in patient utility value and quality of life and are more likely to be depressed. ${ }^{5,6}$

Risk factors associated with the development and progression of DR include prolonged hyperglycemia, hypertension, and hyperlipidemia. ${ }^{7-9}$ Although not fully understood, it is believed that advanced glycation end products contribute to the initiation and progression of DR by breaking down the inner blood retinal barrier and by upregulating vascular endothelial growth factor (VEGF) and intercellular adhesion molecule-1 (ICAM-1). ${ }^{10-12}$ VEGF is a potent angiogenic and vasopermeability stimulus whereas ICAM-1 contributes to leukocyte adhesion resulting in capillary occlusion and vascular cell death. ${ }^{13-15}$ Chronic hyperglycemia is also implicated in enhanced lowdensity lipoprotein peroxidation, which contributes to diabetic vascular disease. ${ }^{16}$ Hyperlipidemia is further associated with increased blood viscosity and alterations in the fibrinolytic system. ${ }^{17,18}$

Hypertension is thought to contribute to endothelial damage as a result of increased shear stress from loss of retinal vascular autoregulation. ${ }^{19}$ Endothelial damage, basement membrane thickening, and pericyte loss result in macular edema, microaneurysm formation, and capillary nonperfusion. ${ }^{20}$ Progressive retinal ischemia may induce neovascularization of the iris, disc, and retina resulting in vitreous hemorrhage (VH) and tractional retinal detachment. Other findings that may be present at any stage of DR include cotton wool spots, intraretinal hemorrhages, and hard exudates.

\section{Control of Systemic Risk Factors}

In addition to regular ophthalmic screening, systemic control of modifiable risk factors is an important adjunct to the management of the ocular complications of DM. It is well-known that rigorous control of blood glucose reduces the incidence of microvascular complications and retinopathy in individuals with type 1 or $2 \mathrm{DM}^{21,22}$ Among the numerous agents available to control blood glucose levels, it is important to note that the thiazolidinediones (glitazone) class of oral hypoglycemic agents used to reduce insulin resistance in type 2 diabetics has been associated with fluid retention and the development of macular edema in $5-15 \%$ of individuals. ${ }^{23,24}$ Resolution of macular edema in these patients occurred over variable periods after discontinuing pioglitazone or rosiglitazone, but was not necessarily associated with an improvement in vision.

In addition to hyperglycemia, hypertension and hyperlipidemia have also been identified as risk factors associated with the development and progression of DR. Tight blood pressure control has been associated with a 34\% reduction in the progression of retinopathy by two or more steps on the Early Treatment Diabetic Retinopathy (ETDRS) scale over 7.5 years and a $47 \%$ reduction in loss of three or more lines of vision as measured with an ETDRS chart. ${ }^{25}$ Hyperlipidemia has been associated with an increased risk of the presence and development of retinal hard exudates and loss of visual acuity. ${ }^{26}$ Treatment of hyperlipidemia with oral agents has been found to reduce retinal hard exudates and microaneurysms. However, it is unclear if an improvement in vision will accompany the retinal changes. ${ }^{27}$

Classification and Treatment of $D R$

The management of DR is dictated primarily by the stage of retinopathy present. DR is broadly categorized as being either non-proliferative or proliferative depending on the absence or presence, respectively, of neovascularization of the iris, disc, or
Dal W Chun, MD, is a medical and surgical vitreoretinal specialist and attending physician at the Walter Reed Army Medical Center serving active duty and retired military personnel and their families. He is an active member of the American Academy of Ophthalmology and is a consultant for the Academy's Digital Media Committee. He is a recent graduate of the Tufts-New England Eye Center vitreoretinal fellowship program in Boston, Massachusetts and has completed an ophthalmology residency at the Walter Reed Army Medical Center in Washington, DC. 
retina. Non-proliferative DR (NPDR) is further classified as being mild, moderate, severe, or severe depending on the number and distribution of microaneurysms, intraretinal hemorrhages, venous beading, and intraretinal microvascular abnormalities. ${ }^{28}$ The severity of NPDR is used to determine followup interval based on the risk of progression to proliferative diabetic retinopathy (PDR).

PDR is further categorized as PDR without highrisk characteristics, PDR with high-risk characteristics, and advanced PDR depending on the degree of neovascularization of the disc (NVD) or retina-neovascularization elsewhere (NVE)-and the presence of vitreous or pre-retinal hemorrhage. PDR is deemed high-risk if there is NVD greater than $1 / 4$ to $1 / 3$ disc area, or any NVD with vitreous or pre-retinal hemorrhage, or NVE greater than or equal to $1 / 2$ disc area with vitreous or pre-retinal hemorrhage. ${ }^{29}$ For eyes that have reached high-risk PDR, scatter panretinal photocoagulation (PRP) has been shown to reduce the incidence of severe vision loss (visual acuity worse than $5 / 200$ ) by $50 \%$ over five years. In general, eyes that do not meet highrisk PDR criteria should be followed closely with prompt treatment should high-risk characteristics develop. However, early treatment is recommended in certain situations such as for older type 2 diabetics with severe NPDR or early PDR or if follow-up cannot be assured. ${ }^{30}$

Other complications that may occur with PDR include $\mathrm{VH}$, retinal detachment, and neovascular glaucoma. The Diabetic Retinopathy Vitrectomy Study determined that for recent severe diabetic $\mathrm{VH}$ (VH reducing visual acuity to 5/200 or worse) for at least one month, eyes that underwent early vitrectomy fared better than those in the deferral group (observation for at least one year prior to vitrectomy). ${ }^{31}$ This difference was significant for type 1 diabetics with $36 \%$ of the early treatment group attaining a visual acuity of $10 / 20$ or better after two years compared with only $12 \%$ in the deferral group. No such benefit was seen in type 2 diabetics. However, with recent improvements in surgical techniques and instrumentation, it may be reasonable to recommend early vitrectomy for both type 1 and type 2 diabetics with severe $\mathrm{VH}$, particularly if there is bilateral dense $\mathrm{VH}$ or if there is a severe $\mathrm{VH}$ in the better eye of an individual who is otherwise functionally monocular.

Tractional retinal detachments are a major complication of PDR that may cause irreversible vision loss. Small, peripheral tractional detachments may be monitored without intervention, but larger detachments or those involving the macula generally require vitrectomy, membrane peeling, and endolaser. Surgical technique and instrumentation vary according to the particular case and surgeon preference, but may involve the use of intraocular forceps, scissors, lighted picks, and viscodissection to separate adherent fibrovascular tissue and posterior hyaloid from the underlying retina. ${ }^{32,33}$ As with other complicated retinal detachments, long-acting tamponade with sulfur hexafluoride, perfluopropane, or silicone oil may also be required to attain apposition of the retina to the underlying retinal pigment epithelium. ${ }^{34-36}$

The development of anti-VEGF compounds for the treatment of age-related macular degeneration has generated interest in targeting VEGF in the treatment of PDR. Bevacizumab (Avastin) is a recombinant humanized monoclonal antibody that binds all isoforms of VEGF with high affinity and is approved by the US Food and Drug Administration (FDA) for the treatment of metastatic colorectal carcinoma. ${ }^{37}$ Intravitreal bevacizumab has been employed in the treatment of neovascular age-related macular degeneration and has been found to induce regression of neovascularization in PDR and hasten the resolution of diabetic $\mathrm{VH} .{ }^{38-41}$ Pegaptanib (Macugen) has also been reported to induce the regression of neovascularization in PDR. ${ }^{42}$ Other cytokines implicated in the pathogenesis of PDR that may someday be targeted by treatments include insulinlike growth factor-I, interleukin-6, transforming growth factor beta 2 , and fibroblast growth factor. ${ }^{43-46}$

\section{Diabetic Macular Edema}

Diabetic macular edema (DME) is the leading cause of vision loss in individuals with DM and can occur at any stage of DR. It results from leakage of fluid from incompetent retinal capillaries that have undergone pericyte loss with resultant microaneurysm formation. ${ }^{20}$ The accumulation of fluid typically occurs in the outer plexiform layer, which leads to distortion of the retinal architecture and reduced vision. With chronicity, DME can form hard exudates composed of lipids and proteinaceous material.

The presence and distribution of retinal thickening and hard exudates determines whether or not DME is considered 'clinically significant.' Clinically significant macular edema (CSME) occurs when there is retinal thickening at or within $500 \mu \mathrm{m}$ of the center of the macula, hard exudates at or within $500 \mu \mathrm{m}$ of the center of the macula with adjacent retinal thickening, or retinal thickening equal to or greater than one disc area within one disc diameter 
from the center of the macula. ${ }^{48}$ Retinal thickening or hard exudates not meeting these criteria are generally observed without therapy unless CSME develops. CSME treatment with focal or grid laser photocoagulation has been found to reduce the incidence of moderate vision loss (doubling of the visual angle) compared with controls after three years. ${ }^{49}$ Resolution of CSME may take several months and may require multiple treatments.

Recurrent or recalcitrant CSME despite adequate laser treatment may require alternative therapies. Pars plana vitrectomy has been found to reduce retinal thickness and improve vision, particularly if there is an associated taut posterior hyaloid. ${ }^{50,51}$ Although advocated by some, it is unclear if vitrectomy with or without removal of the internal limiting membrane provides any benefit if CSME is not accompanied by an epiretinal membrane or taut posterior hyaloid..$^{52,53}$ Vitrectomy may also be considered for removal of massive submacular hard exudates but visual outcomes have not been consistently positive across different studies. ${ }^{54,55}$

Intravitreal triamcinolone acetate (IVTA) has also been used alone or in combination with vitrectomy in cases of refractory CSME. The most common dose administered in the US is $4 \mathrm{mg}$ in $0.1 \mathrm{cc}$. Eyes treated with IVTA have a reduction in central macular thickness as measured by optical coherence tomography with an average duration of effect lasting approximately three months from the time of injection. ${ }^{56}$ However, improvements in central retinal thickness may not necessarily be accompanied by an improvement in visual acuity and recurrence of DME may occur, requiring additional therapy. ${ }^{57-59}$ Complications of IVTA warranting careful consideration before its use include endophthalmitis, elevated intraocular pressure, and progression of cataract. . $^{57,60-62}$
Long-acting intraocular corticosteroid implants are under investigation for use in DME and other chronic ocular conditions such as posterior uveitis. Fluocinolone acetonide (Retisert) and dexamethasone (Posurdex) have both yielded positive results in preliminary studies showing an improvement in retinal thickness and visual acuity. ${ }^{63,64}$

As with PDR, DME has been associated with increased levels of certain vasopermeability factors, most notably VEGF.6 ${ }^{65}$ In a recent phase II trial, pegaptanib $0.3 \mathrm{mg}$ and $1 \mathrm{mg}$ were found to significantly improve visual acuity at 36 weeks compared with baseline. ${ }^{66}$ The $0.3 \mathrm{mg}$ dose was also associated with a significant reduction in the thickness of the central point of the central subfield compared with sham. One case of culture-negative endophthalmitis was reported but there were no reports of elevated intraocular pressure or progression of cataract.

DR continues to be a major cause of visual morbidity. Strict control of modifiable systemic risk factors and timely surveillance of ophthalmic complications help to reduce the incidence and severity of DR. Current treatments are often effective in preserving or restoring vision, but many individuals exhibit recurrence, recalcitrance, or progression despite therapy. Newer treatments targeting vasopermeability and vasogenic stimuli offer potential therapeutic alternatives for these individuals. Additional research into the pathogenetic mechanisms that underlie the development of the ocular complications of DM and clinical trials evaluating the efficacy of novel therapies may yield alternatives to current treatments for such patients.

A version of this article containing full references can be found in the Reference Section on the website supporting this briefing (www.touchsensorydisease.com).

\section{References}

1. Centers for Disease Control and Prevention (CDC), MMWR Morb Mortal Wkly Rep (2003);52(35):pp. 833-837.

2. Kempen JH, O'Colmain BJ, Leske MC, et al., Arch Ophthalmol (2004);122(4):pp. 552-563.

3. Klein R, Klein BE, Moss SE, et al., Arch Ophthalmol (1984);102(4):pp. 520-526.

4. Porta M, Bandello F, Diabetologia (2002);45(12):pp. 1,617-1,634.

5. Brown MM, Brown GC, Sharma S, et al., Am J Ophthalmol (1999);128(3):pp. 324-330.

6. de Groot M, Anderson R, Freedland KE, et al., Psychosom Med (2001);63(4):pp. 619-630.

7. Kohner EM, Aldington SJ, Stratton IM, et al., Arch Ophthalmol (1998);116(3):pp. 297-303.

8. Chew EY, Klein ML, Ferris FL 3rd, et al., Arch Ophthalmol (1996);114(9):pp. 1,079-1,084.

9. Klein R, Klein BE, Moss SE, et al., Arch Intern Med (1989);149(11):pp. 2,427-2,432.

10. Stitt AW, Bhaduri T, McMullen CB, et al., Mol Cell Biol Res Commun (2000);3(6):pp. 380-388.

11. Lu M, Kuroki M, Amano S, et al., J Clin Invest (1998);101(6):pp. 1,219-1,224.

12. Kunt T, Forst T, Harzer O, et al., Exp Clin Endocrinol Diabetes (1998);106(3):pp. 183-188. 
13. Adamis AP, Miller JW, Bernal MT, et al., Am J Ophthalmol (1994);118(4):pp. 445-450.

14. Senger DR, Perruzzi CA, Feder J, et al., Cancer Res (1986);46:pp. 5,629-5,632.

15. Connolly, ES, Winfree, CJ, et al., J Clin Invest (1996);97:pp. 209-216.

16. Kawamura M, Keinecke J, Chait A, J Clin Invest (1994);94(2):pp. 771-778.

17. Solerte SB, Fioravanti M, Patti AL, et al., Acta Diabetol Lat (1987);24(4):pp. 341-349.

18. Asakawa H, Tokunaga K, Kawakami F, J Diabetes Complications (2000);14(3):pp. 121-126.

19. Rassam SM, Patel V, Kohner EM, Exp Physiol (1995);80(1:)pp. 53-68.

20. Lee PF, Am J Ophthalmol (1968);65(5):pp. 688-695.

21. Diabetes Control and Complications Trial Research Group, Arch Ophthalmol (1995);113:pp. 36-51.

22. The UK Prospective Diabetes Study Group, Lancet (1998);352:pp. 837-853.

23. Colucciello $M$, Arch Ophthalmol (2005);123(9):pp. 1,273-1,275.

24. Ryan EH Jr, Han DP, Ramsay RC, et al., Retina (2006);26(5):pp. 562-570.

25. UK Prospective Diabetes Study Group, Br Med J (1998);317:pp. 703-713.

26. Chew EY, Klein ML, Ferris FL 3rd, et al., Arch Ophthalmol (1996);114(9):pp. 1,079-1,084.

27. Gordon B, Chang S, Kavanagh M, B. et al., Am J Ophthalmol (1991);112(4):pp. 385-391.

28. Early Treatment Diabetic Retinopathy Study Research Group, Ophthalmology (1991);98(5 Suppl):pp. 823-833.

29. The Diabetic Retinopathy Study Research Group, Ophthalmology (1981);88(7):pp. 583-600.

30. Ferris F, Trans Am Ophthalmol Soc (1996);94:pp. 505-537.

31. The Diabetic Retinopathy Vitrectomy Study Research Group, Arch Ophthalmol (1985);103(11):pp. 1,644-1, 652.

32. Aaberg TM, Abrams GW, Ophthalmology (1987);94(7):pp. 775-779.

33. Grigorian RA, Castellarin A, Fegan R, et al., Br J Ophthalmol (2003);87(6):pp. 737-741.

34. Brourman ND, Blumenkranz MS, Cox MS, et al., Ophthalmology (1989);96(6):pp. 759-764.

35. Lean JS, Boone DC, Azen SP, et al., Arch Ophthalmol (1992);110(6):pp. 770-779.

36. McCuen BW, Azen SP, Stern W, et al., Retina (1993);13(4):pp. 279-284.

37. Presta LG, Chen H, O'Connor SJ, et al., Cancer Res (1997);57(20):pp. 4,593-4,599.

38. Oshima Y, Sakaguchi H, Gomi F, et al., Am J Ophthalmol (2006);142(1):pp. 155-158.

39. Spaide RF, Fisher YL, Retina (2006);26(3):pp. 275-278.

40. Grisanti S, Biester S, Peters S, et al., Am J Ophthalmol (2006);142(1):pp. 158-60.

41. Avery RL, Pieramici DJ, Rabena MD, et al., Ophthalmology (2006);113(3):pp. 363-372.

42. Krzystolik MG, Filippopoulos T, Ducharme JF, et al., Arch Ophthalmol (2006);124(6):pp. 920-921.

43. Poulaki V,Joussen AM, Mitsiades N, et al., Am J Pathol (2004);165(2):pp. 457-469.

44. Funatsu H, Yamashita H, Shimizu E, et al., Retina (2001);21(5):pp. 469-477.

45. Hirase K, Ikeda T, Sotozono C, et al., Arch Ophthalmol (1998);116(6):pp. 738-741.

46. Sivalingam A, Kenney J, Brown GC, et al., Arch Ophthalmol (1990);108(6):pp. 869-872.

47. Cusick M, Chew EY, Chan CC, et al., Ophthalmology (2003);110(11):pp. 2,126-2,133.

48. Early Treatment Diabetic Retinopathy Study Research Group Ophthalmology (1987);94(7):pp. 761-774.

49. Early Treatment Diabetic Retinopathy Study Research Group, Ophthalmology (1991);98:pp. 766-785.

50. Harbour JW, Smiddy WE, Flynn HW Jr, et al., Am J Ophthalmol (1996);121(4):pp. 405-413.

51. Tachi N, Ogino N, Am J Ophthalmol (1996);122(2):pp. 258-260.

52. Recchia FM, Ruby AJ, Carvalho Recchia CA, Am J Ophthalmol (2005);139(3):pp. 447-454.

53. Kamura Y, Sato Y, Isomae T, et al., Jpn J Ophthalmol (2005);49(4):pp. 297-300.

54. Yang CM, Retina (2000);20(2):pp. 121-125.

55. Takaya K, Suzuki Y, Mizutani H, et al., Retina (2004);24(1):pp. 23-29.

56. Patelli F, Fasolino G, Radice P, et al., Retina (2005);25(7):pp. 840-845.

57. Martidis A, Duker JS, Greenberg PB, et al., Ophthalmology (2002);109(5):pp. 920-927.

58. Massin P, Audren F, Haouchine B, et al., Ophthalmology (2004);111(2):pp. 218-224.

59. Larsson J, Zhu M, Sutter F, Gillies MC, Am J Ophthalmol (2005);139(5):pp. 802-806.

60. Sutter FK, Simpson JM, Gillies MC, Ophthalmology (2004);111(11):pp. 2,044-2,049.

61. Detry-Morel M, Escarmelle A, Hermans I, Bull Soc Belge Ophtalmol (2004);(292):pp. 45-51.

62. Chieh JJ, Roth DB, Liu M, et al., Retina (2005);25(7):pp. 828-834.

63. Pearson P, Levy B, Comstock T, Poster presented at Annual Meeting of the Association for Research in Vision and

Ophthalmology, May 2006.

64. Kuppermann BD, Williams GA, Blumenkranz MS, et al., Poster presented at Annual Meeting of the Association for

Research in Vision and Ophthalmology. May 2006.

65. Funatsu H, Yamashita H, Noma H, et al., Am J Ophthalmol (2002);133(1):pp. 70-77.

66. Cunningham ET Jr, Adamis AP, Altaweel M, et al., Ophthalmology (2005);112(10):pp. 1,747-1,757. 